\title{
Endomyocardial Biopsy
}

National Cancer Institute

\section{Source}

National Cancer Institute. Endomyocardial Biopsy. NCI Thesaurus. Code C51674.

Removal of myocardial tissue for microscopic examination, usually taken from the right heart using a transvenous approach. 